\title{
Research on the practice of information literacy education model based on students' information behavior analysis
}

\author{
Qicun Sun ${ }^{1}$, Chunlei Wang ${ }^{2 *}$ \\ 1,2 Northeast Normal University Library, Changchun, China \\ *wangcl055@nenu.edu.cn
}

Keywords: Information literacy education; Students' information behavior; Academic library

\begin{abstract}
There were a lot of problems in information literacy education of the university under the new information environment. Furthermore, profound changes have taken place in the students' information behavior. The university library should shoulder the important task of information literacy education in colleges and universities. The university library should promote the development of the information literacy education of universities based on the library resources, advanced ideas and excellent talents.
\end{abstract}

\section{The Status Quo and Problems of University Information Literacy Education under the New Information Environment}

In the era of knowledge economy and information age, information has become an important factor in promoting social economy, science and technology, and promoting the development of human society. Information Literacy has become an important indicator for evaluating the overall quality of talents. The information literacy education in China's colleges and universities started late. From the late 1980s to the early 1990s, the State Education Commission (Ministry of Education) requested three times to open the "Document Search and Utilization" course in colleges and universities, and to carry out information literacy education and literature retrieval skills for college students. At present, the implementation of information literacy education in colleges and universities in China is generally completed through courses related to information literacy education, including "computer culture foundation" or "educational technology" and "document retrieval and utilization" courses in normal colleges. However, due to various reasons, such as the lack of training for teachers, the single content of teaching, the weak awareness of students' information, and the lack of cooperation and exchanges among universities across the country, the current situation of information literacy education in China's colleges and universities has become unbalanced. Except for a few university libraries such as Peking University, Tsinghua University, and Shanghai Jiaotong University, the teaching results of most university libraries are not satisfactory. The author conducted an online survey of 11 colleges and universities in Changchun, and 4 of them opened information literacy related courses, accounting for $36 \%$ of the total. This shows that the level of overall information literacy education in colleges and universities in Changchun is relatively backward.

Most colleges and universities have realized the importance of student information literacy education, but how to carry out information literacy education for students, how to cultivate students' information literacy is a problem that most universities have not yet solved. Some schools incorporate information literacy education courses into the training courses related to basic knowledge of computer knowledge. The relevant teachers of the School of Computer Science teach the simple literature and database knowledge in information literacy education in the course of teaching computer knowledge. Some schools have classified information literacy education as a category of library business services. One or two librarians in the relevant departments of the library are responsible for this business all the year round. Due to the single method, the content of the lectures is unchanged all the year round, and the librarians are not full-time teachers, and can not teach and give all the courses that the energy is invested in. The courses carried out are not effective and the students' interest is not high. 


\section{Changes in student information behavior in the new network environment}

Under the new network information environment, the main users of college libraries is students, have undergone profound changes in their information behavior. They tend to rely more on information they get online, rather than relying on a teacher's lectures or learning from textbooks. Nowadays, most of the students in colleges and universities are mainly after 80 s and 90 s. Their personality is more comprehensive. The survey shows that their network behavior mainly includes virtual social, information browsing, online shopping, online video, online games and search engines. In the retrieval and identification of information, they often pursue simpler and more direct methods, rather than spending too much time to identify the value and authenticity of information. In the behavior of information exchange and exchange, they are often more willing to find the information they want from the online communication modules such as virtual communities and online forums, instead of consulting with teachers or senior seniors in the traditional teaching mode. In addition, with the renewal and replacement of electronic products, more and more students rely on mobile devices such as tablets and mobile phones. They get more information from mobile devices, and keep abreast of news updates and the dynamics of friends in their social circles. This change in user information behavior catalyzes the transformation of the library information service model, and it is also urgent to require the library's information literacy education to keep up with the actual needs of users.

The traditional teaching model of classroom teaching does not keep up with the changes in students' new behavior. The traditional teaching and learning emphasizes the leading role of teachers in the classroom. And teaching methods are limited. Teachers spend a lot of time in the classroom to teach textbook knowledge, and spend a lot of time preparing lessons after class, instead of focusing on communication with students. Not good at using popular network means to communicate with students, real-time communication between class and class. Traditional teaching, the teacher is the main body, giving the impression that the teacher is constantly talking, occasionally using heuristic questions and asking questions to the students. Limited to the actual classroom space, and limited teaching aids, classroom teaching is not possible to keep up with the times to follow up on the new changes in students' information behavior, and only transmit some traditional literature retrieval knowledge.

\section{The Advantages of University Libraries as Information Literacy Education}

The library is the center of cultural inheritance, and is the center of information transmission, especially the university library. As an important place for the inheritance of school culture and the procurement and management of electronic resources, the library not only has the objective conditions for carrying out information literacy education, but also Advance with the times to meet the user's new information under the conditions of network information.

\subsection{University libraries are the main institutions for the procurement, management, construction and use of school literature resources}

One of the main functions of current university libraries is to be responsible for the procurement, management and use of school literature resources. Every year, the school invests a large amount of funds in the construction of document resources to meet the needs of the teachers and students of the school, and facilitates the inquiry, retrieval, download and lending of teachers and students. The end users of the literature resources are the teachers and students of the school, and the funds for the procurement of literature resources are derived from the school funds. The library acts as the central institution. On the one hand, it is necessary to investigate the needs of teachers and students, and communicate well with the department to facilitate the procurement of documents. When resources are available, there is a spectrum in mind. On the one hand, the library should be sold to the seller of the literature resources, generally the database vendor, and communicate well, using the most economical and effective method to achieve the purpose of purchasing. In order to maximize the benefits pursued by database vendors, especially their own copyrights for literature resources, especially electronic resources, the price of electronic resources has increased year by year. In this 
process, libraries need to seek inter-library cooperation to form a procurement alliance and jointly respond. On the other hand, libraries need to constantly research and investigate the use of electronic resources, not only depending on the amount of use, but also how much to buy and how much to buy. Instead, find the optimal ratio for the use of electronic resources within the scope of the funds that the school can afford.

\subsection{University libraries have rich collections and information products needed for information literacy education that is not available in general departments}

The history of university libraries is basically the same as the history of school construction. Due to the historical accumulation, the library has formed a variety of collections with rich and distinctive features. At the same time, the library, as an important place for students to gather, keeps pace with the information age and will form a good interaction with various database companies or enterprises. Most of these companies use the library as an important gathering place for students to promote their products. In addition, the relevant departments of the school, such as the Student Union and the Propaganda Department, will also use the library's wide and bright physical space to use various activities to promote related activities or arrange interactive activities with students. Therefore, advanced electronic devices such as reading panels, e-book readers, electronic newspaper readers, self-service lending machines, advertising machines, LED publicity boards, tablet computers, etc. are the first to enter the library to enter the reader's field of vision, which is convenient for readers. At the same time, the library has also greatly improved the existing premises, and set up physical spaces such as digital learning space, digital multimedia room, and reading space and other convenient reading, discussion and research. The library has also become a good place for college students to improve their information literacy through new media in the new information product era.

\subsection{The university library has a newly introduced librarian team with high quality and high network skills}

Subject librarians in university libraries are familiar with the professional and library collections of colleges and universities, and have good information quality, which can be explained and demonstrated by college students anytime and anywhere. Most of the librarians who have entered the university library are graduate students who have graduated from master's degree or above. Moreover, the profession of recruited personnel is not limited to graduate students who graduate from library and information science. In order to fully develop the library business, each university library has recruited graduates who can satisfy all the majors of the school. These graduates come from the faculty, understand the electronic resources construction of the department, understand the information needs of the teachers and students of the department, and can change the role of the students from the department to the library librarian. I deeply understand the ways and modes that can be used to better serve the teachers and students of the department. They have a better grasp of the information behavior of college students than the traditional librarians, and can put themselves in the shoes of the students, thus achieving a more thoughtful and more practical service to the teachers, and more comfortable in the information literacy education of the students.

\section{Based on the electronic resources of the library, rationally apply the long tail effect, pay attention to the individualized guidance of students' information behaviors, and carry out information literacy general education courses with various forms and novel contents}

On the basis of many years of reference consulting business, the Northeast Normal University Library opened an elective course on "Discovery, Acquisition and Utilization of Literature Resources" in the first year of graduate school. Become an important part of school information literacy education. From the curriculum setting, 10 classes are set up according to different topics, and 10 teachers are divided into two campuses for teaching. Each teacher is the most professional librarian who is most familiar with the topic. The topic involves the use of Chinese and foreign books, the acquisition and use of foreign language periodicals and master's thesis, the interlibrary loan and 
document transmission, the use of reference databases, and other traditional literature information retrieval and utilization knowledge, as well as personal academic evaluation, Novel information management and utilization literacy skills such as information visualization, information resources on the Internet, and knowledge management. The results are not tied to the final exam. Instead, the usual topics and assignments are placed on the course platform for students to choose. Although the form of class is based on the combination of theory and actual machine, it also adopts novel forms such as network teaching, network survey, and online marking. The library also uses the advanced course management and utilization platform (Blackboard and Moodle platform) to achieve real-time interaction and online communication with students, and submit online assignments and network transcripts. These forms are not limited to specific physical space and time, as long as students have access to the Internet. Make students have no sense of restraint, and will not be unqualified because one or two exams are not ideal.

Although the library uses a variety of methods to achieve information literacy education for students, it is impossible to meet the information literacy education needs of all grades in the school. Information literacy education is a subtle and long-term educational process. Is it necessary to invest more librarians and invest more resources to cover the information literacy education of the whole school? The author believes that this is not feasible, even if it can achieve the effect will not be too good. The traditional cramming teaching can't satisfy the students' knowledge needs, let alone the information literacy, which relies heavily on the quality skills of external information equipment. Moreover, students' thoughts and behaviors tend to be diversified and personalized, so libraries need to be able to adopt more individual and reasonable education methods based on this new change. Utilizing the "long tail effect", the information needs of the "head", the largest demand part, are met with reasonable and effective physical space and electronic resources that meet the actual needs of the school. The use of thematic and personalized information literacy education generalization course to achieve the "tail" is the student's differentiated and personalized information needs.

\section{Summary}

In short, under the new information environment, students' information behavior has undergone profound changes. As an important base for school information dissemination, libraries should pay attention to the changes of users' information behaviors in real time, so as to undertake the information literacy education of college students in a targeted manner.

\section{References}

[1] N. Hoffman, S. Beatty, P. Feng, J. Lee, Teaching research skills through embedded librarianship, Reference Services Review, vol. 45, pp.211-226, 2017.

[2] B. C. Wu, Research on Information Resource Integration and Service Model Based on User Behavior, Journal of Modern Information, vol.04, pp.51-53, 2009.

[3] Y. Zhou, Research on Information Behavior of Group Users in Network Environment, East China Normal University, 2010.

[4] ]Z. L. Xiao, Information Literacy Education and the Mission of University Libraries, Journal of Academic Libraries,vol.03, pp.2-5, 2005. 